\title{
A road to ethics: a new experience of retraction
}

\author{
Hafez Mohammadhassanzadeh ${ }^{1}$, Amin Beigzadeh $^{2 *}{ }$ Mehrdad Nazarieh $^{3}$ \\ ${ }^{1}$ Cardiovascular Research Centre, Tabriz University of Medical Sciences, Tabriz, Iran \\ ${ }^{2}$ Research Centre for Health Services Management, Institute for Futures Studies in Health, Kerman University of Medical Sciences, \\ Kerman, Iran \\ ${ }^{3}$ Department of English Language, Faculty of Foreign Languages, Kerman Institute of Higher Education, Kerman, Iran
}

\section{To the Editor}

Every journal finds its fundamentals in the course of time by the validity and originality of its published literature. This is validated if authors keep diligence and honesty when they conduct their research and submit their work in a journal. But at times what comes out of a scientific research is not always valid and reliable because there has not been an appropriate control on the work or researchers did not thoroughly conduct and report the results. Thus, it is very important that journals keep an increasingly close eye for the detection of scientific misconduct (1-6).

In this issue of the Journal of Emergency Practice and Trauma, we decided to highlight an important face of research which is hidden in its nature and plays a detrimental role in the scientific world of research. To cut a long story short, it was not too long for the Report of Health Care journal to publish its second issue that the editor in charge realized a scientific misconduct and took the case under investigation before deciding on a course of action. After taking the case under investigation, it became evident that they must retract the paper titled "The frequency and pattern of antibiotic resistance among Klebsiella spp. isolated from nosocomial infection in Khorramabad hospital" for scientific misconduct. This misconduct was due to the fact that authors of this paper previously published their paper elsewhere and did not take this case of redundant publication (presenting the same data in another publication) into account. The Committee on Publication Ethics (COPE) defines retraction as "a mechanism for correcting the literature and alerting readers to publications that contain seriously flawed or erroneous data that their findings

Received: 17 April 2015; Accepted: 6 June 2015;

Published online: 8 June 2015

*Corresponding author: Amin Beigzadeh, Research Centre for Health Services Management, Institute for Futures Studies in Health, Kerman University of Medical Sciences, Kerman, Iran.

Email: a.beigzadeh@kmu.ac.ir

Competing interests: The authors declare that no competing interests exist.

Funding information: There is none to be declared.

Citation: Mohammadhassanzadeh H, Beigzadeh A, Nazarieh M. A road to ethics: a new experience of retraction. Journal of Emergency Practice and Trauma 2016; 2(1): 1-2. doi: 10.15171/jept.2015.04 and conclusions cannot be relied upon" (7). As the editor came into a final conclusion to proceed with the retraction policy, the authors did not agree with this firm decision and articulated that they had only disguised the title and the abstract of the paper in case referees or the editor in charge would not be able to reveal the paper that had been published elsewhere. More importantly, they thought that this disguise would not make any problems and did not consider this as a scientific misconduct. When they encountered the harsh decision of retraction from the editor in charge, they claimed for the removal of their paper from the journal website but in this extreme circumstance the editor in charge retracted the paper without the authors' consent as they did not voluntarily accepted a retraction. In recent years there has been a global zest for academia to publish their work in well-rounded journals. This trend is not only ubiquitous in developed countries but also in developing countries as well. One of the areas of concern is the validity, quality, and originality of the papers which are submitted by the authors to these journals. In this run, journals are confronted with issues such as plagiarism, unethical research, multiple submissions, duplicate publications, and scientific fraud (data fabrication and experimental error). Above all, what is really important is how vigilant journals would be to investigate, identify, and report such occurrences. This is more prominent in journals which have recently started a career in the publishing arena. These misconducts give journal editors credit to retract publications that do not meet the requirements of an acceptable scientific paper. We should bear in mind that the main target of retraction is correction of the literature and ensuring its integrity without ruining the reputation and credibility of authors who submit the work. Therefore, a comprehensive and cautious investigation is needed to retract a paper as delaying or taking the paper for granted has its own pros and cons.

Regarding the fact that this is the first retraction of an article in an Iranian context, we strictly express that scientific misconduct, as one of the many challenges to be dealt with in an educational setting, must be carefully scrutinized. We should also express that in order to restrain such misconduct, there should be a different approach of evaluating faculty and research community in order to promote 
them. This cannot be obtained without any decisive actions from the authoritative bodies in charge of publishing or any governmental agency in this setting. This opens the way for other indices in order to assess faculty and researches apart from the number of articles that they have to publish in a journal. The editors of the Report of Health Care sadly retracted the aforementioned article as there was not any other course of actions to be taken on their part. We believe that the violation of the standard codes of academic conduct and ethical behavior in the scientific world of research should not be tolerated and taken for granted at any level as the consequences can be really damaging for both perpetrators and any individual who exposes it $(8,9)$.

\section{Ethical issues}

Not applicable.

\section{References}

1. Enserink M. Scientific ethics. Fraud-detection tool could shake up psychology. Science 2012; 337(6090): 21-2.

2. Hein J, Zobrist R, Konrad C, Schuepfer G. Scientific fraud in 20 falsified anesthesia papers: detection using financial auditing methods. Anaesthesist 2012; 61(6): 543-9.

3. Kumar MN. Dealing with misconduct in biomedical research: a review of the problems and the proposed methods for improvement. Account Res 2009; 16(6): 307-30.

4. Miller DR. Publication fraud: implications to the individual and to the specialty. Curr Opin Anaesthesiol 2011; 24(2): 154-9.

5. Schupfer G, Hein J, Casutt M, Steiner L, Konrad C. [From financial to scientific fraud: methods to detect discrepancies in the medical literature]. Anaesthesist 2012; 61(6): 537-42.

6. Wood BD. Academic misconduct and detection. Radiol Technol 2010; 81(3): 276-9.

7. The Committee on Publication Ethics. Available at: http://publicationethics.org/. Accessed May 1, 2015.

8. Xie Y. What are the consequences of scientific misconduct? Ars Technica. http://arstechnica.com/ science/2008/08/what-are-the-consequences-forscientific-misconduct/. Updated Aug 12, 2008.

9. Redman BK, Merz JF. Scientific Misconduct: Do the Punishments Fit the Crime? Science 2008; 321(5890): 775. 